\title{
Difficulties experienced by newly-graduated nurses in Turkey: A qualitative study of the first six months of employment
}

\author{
Betül Sönmez * Aytolan Yıldırım \\ Nursing Administration Department, Florence Nightingale Faculty of Nursing, Istanbul University, Istanbul, Turkey
}

Received: August 2, 2015

DOI: $10.5430 /$ jnep.v6n1p104

\author{
Accepted: October 8, 2015 \\ Online Published: October 21, 2015 \\ URL: http://dx.doi.org/10.5430/jnep.v6n1p104
}

\begin{abstract}
Objective: The aim of this study was to identify the difficulties experienced by newly-graduated nurses within the first six months of employment.

Methods: This research was designed as a qualitative study based on content analysis. The study sample consisted of nurses who had graduated from nursing in 2010, have been working at a public university hospital in Istanbul for at least six months, and were selected via "maximum variation sampling" from purposeful sampling methods. Data were collected via semi-structured in-depth interviews. The data collection process ended at the end of the fifteenth interview when data saturation was reached.

Results: The results obtained based on the qualitative sampling isolated four general themes explaining the difficulties newlygraduated nurses experience within the first six months of their employment: lack of knowledge, heavy workload, lack of clinical skills and communication difficulties.

Conclusions: The findings of this first qualitative study conducted with nurses in Turkey are in support of the related literature. Among the difficulties experienced by the newly-graduated nurses within the first months of employment, educators should address the issue of lack of knowledge and managers should address the other issues raised.
\end{abstract}

Key Words: Newly-graduated, Nurses, Reality shock, Qualitative study, Interview, Turkey

\section{INTRODUCTION}

Forty years ago, Kramer defined the conditions nurses experience at the beginning of their career due to the differences between the real world and the "ideal" world of nursing as "reality shock". While nurses are expected to adapt to their working conditions as soon as possible around the world due to the nursing shortage, it is still being researched whether they have the necessary knowledge, skills, and confidence or not. ${ }^{[1]}$ Studies evaluate the transition from being a nursing student to professional nursing as a traumatic and stressful period. ${ }^{[2-6]}$

Studies conducted with newly-graduated nurses report that the newly-graduated nurses experience stress, anxiety, and disappointment during the first months (up to 9-12 months) of their employment due to insufficient clinical skills, heavy workload, inability to spare enough time for patients, prioritization and decision-making. ${ }^{[1,2,4,7-11]}$ For over thirty years, researcher nurses and health service managers have been investigating the factors impacting the stress experienced by newly-graduated nurses in their transition to professional life.

\footnotetext{
*Correspondence: Betül Sönmez; Email: betulsnmz@yahoo.com; Address: Nursing Administration Department, Florence Nightingale Faculty of Nursing, Istanbul University, Istanbul, Turkey.
} 
These factors are grouped as professional and organizational factors. While professional factors include role ambiguity, lack of knowledge and skills, increased responsibility, and realization of individual accountability, organizational factors include time pressure, role limitations, nurse shortage, heavy workload, task-centered operations rather than patient centered operations, shift work, high job-related expectations, insufficient peer support, inability to reach physicians, lack of basic resources, and low organizational commitment. ${ }^{[3,12]}$

In Mooney's ${ }^{[2]}$ study, interviewed nurses reported that the tasks were carried out as routines and were not patientcentered, and defined hierarchical behaviour and strict rules. It was also reported that they were not taught how to manage time or to prioritize their workload during their formal education:

"This is complete chaos. I have five patients to care for at the same time. How should I decide which patient is more important? What is the 'right thing' to do? While choosing between patients, I am afraid of hurting a patient or of a patient dying."[11]

In another study, ${ }^{[12]}$ a nurse reported that $\mathrm{s} /$ he was warned by other nurses, stating that "it was unacceptable to talk to patients" when s/he talked to patients. Additionally, factors such as facing death, legal and organizational pressure regarding drug management, and relations with other health workers also impact the newly-graduated nurses' adaptation to their new roles. ${ }^{[9]}$

Quantitative studies conducted in Turkey support the findings mentioned above. ${ }^{[8,10,13,14]}$ Nurses evaluate the transition to professional nursing as a difficult period. ${ }^{[8,10]}$ In Uzun and Arslan's ${ }^{[13]}$ study, it was determined that the majority of nurses reported that their expectations of and experiences in their first year were different and that all of them had difficulty in clinical practices. Another stress factor experienced during this period was reported as "working with uncooperative nurses". ${ }^{[10,14]}$ The focus of this study was to identify the difficulties experienced by newly-graduated nurses in Turkey and the associated reasons, by employing a qualitative research design.

\section{METHOD}

\subsection{Objective}

This is a qualitative study based on content analysis, aimed at identifying the difficulties experienced by newly-graduated nurses during the first six months of their employment.

Published by Sciedu Press

\subsection{Setting and sample}

The participants included in the study were nurses who had graduated from a bachelor's program in nursing in 2010 and had been employed for at least six months at a public hospital in Istanbul. Among purposive sampling methods classified by Patton, "maximum variation" method was used in determining the samples. The purpose in maximum variation sampling is to create a relatively small sample and maximize the variety of experience related to the phenomenon of interest. $^{[15]}$ Accordingly, newly-graduated nurses for sampling were chosen with special attention to having a variety of backgrounds, such as nursing schools being private or state funded, with different locations, and chosen from departments with different facilities, such as adult and children's services, intensive care and special units, etc. As a result of repetitive data, data saturation was determined and data collection terminated at 15 th interview.

\subsection{Data collection}

Data were collected via semi-structured in-depth interviews. The interviews began on June 2011 and ended on December 2011 due to the process of getting permission for the study and considering the criteria of at least six months work experience in sample group. The interviews were conducted in the meeting rooms of the units the nurses worked at or in the researcher's office. The interviews took 30 minutes on average. Voice-recording devices were used to record the data collected during the interviews. An Interview Guide prepared in light of the literature was used throughout the interviews in order to guide the interviewing researcher.

\subsection{Ethical consideration}

Approval from the Clinical Research Ethical Committee and permission from the hospital management were obtained prior to conducting the study. A voluntary informed consent form was signed by participants prior to interviews. The participants were assured that their identities and voice records would be kept confidential.

\subsection{Data analysis}

The researchers made a transcription of the voice records from each interview. The basic process in (inductive) content analysis is to gather similar data within a framework of certain concepts and themes and interpret them in an understandable way. ${ }^{[16]}$ MaxQDA 10 Plus qualitative data analysis software was used in the process of data encoding. Following initial independent coding, data were grouped under different themes after discussion of both researchers, and the results obtained were interpreted at the final stage. In order to increase reliability, two participants were provided with feedbacks to verify the coded phrases. 


\section{Results}

Four themes were identified to explain the difficulties experienced by the newly-graduated nurses during the first six months of their employment, based on the data gathered from the qualitative sample.

\subsection{Communication difficulties}

It was reported that the nurses experienced difficulties in communicating with their nursing colleagues, nurse managers, and physicians during the first months of their employment.

Z2: ... it was a terrible time... there were jealousy, envy issues among our friends [nurses] and so many were leaving their work for another to finish... We work directly with the professors [physicians], which is such a different stress we learned about. The continuous yelling, the anger towards you... such things can happen.

Some of the nurses, on the other hand, reported that they felt that they were always watched for their shortcomings in nursing practices, experienced "scolding", and were told to have formal communications by using phrases such as "sister".

E1: In the beginning... They were always watching out for our shortcomings and telling us we did this and that wrong. Even after a night shift we could not really leave work, they would keep calling.

\subsection{Lack of clinical skills}

Nurses reported having difficulty with starting peripheral intravenous catheterization (IVs), aspiration and use of medical devices during the first months of employment. The majority of nurses reported that they experienced difficulty specifically with starting IVs though they had technical knowledge, and felt that their skills were inadequate.

S: Here [pediatrics], the most common issue we have is starting IVs... it is much shorter than in adults. Somehow I got used to it though.

U: ... I had such a hard time in starting IVs. We were alone on night shifts. I kept trying over and over and could not do it. I would call the supervisor, who would either come over and do it or send someone else over to take care of it. Apparently I called on almost every night shift.

Another nurse reported "fear of killing a patient" in her early days while aspirating patients:
P: Honestly, I was scared even to aspirate a patient in the beginning. During those 1-2 seconds without breathing, it made me fear that I would cause their death."

\subsection{Lack of knowledge}

A few of the nurses reported that lack of knowledge caused stress:

Z1: I had a difficult time... because you try to get to know the patients and their diseases. A patient returns from surgery and you forget it all... then you panic thinking "what can I do now?"

G: ... and then there was that fear... what if someone comes and asks me something... I'd better read up about this too...

The topics nurses reported lack of knowledge in were mostly pharmacology, followed by diseases, surgeries, examinations, and laboratory results. The pharmacological topics they felt insufficient in were drug names, drug effects, preparation of drug infusions (nitroglycerine, dopamine, etc.) mostly used in intensive care, and calculation of drug dosages.

P: There were so many things I did not know. I didn't really fully know how to use nitroglycerine, dopamine...

Additionally, they stated that they felt they did not have sufficient knowledge of diseases, surgical procedures, and blood tests.

E3: ... there are so many types of surgery that I still find myself asking what surgery this is or which part of the body this is performed in...

A few of the nurses reported having difficulties calculating drug doses for pediatric patients.

$\mathrm{N}$ : I had not even learnt how to calculate a drug dosage. I mean maybe I was taught how to do it but I had a very hard time. I can hardly do a mathematical calculation. That really upset me that I kept thinking did I learn these already, how can I not know it. . .

G: ...you prepare it for a little child, a one-month old, a new-born, a premature baby... calculating drug doses for so many patients can be very difficult for a new graduate.

Additionally, a nurse reported being unable to interpret examination and test results, and stated that his/her formal 
education and personal attitude towards the profession affected this. A few nurses stated that they consult other nurses or physicians when they feel that they lack knowledge. In general, all nurses reported that they try to overcome their lack of knowledge by asking others for help or by reading about and trying out the tasks themselves.

\subsection{Heavy workload}

Another reason that nurses have difficulty in their first months at work is the heavy workload, which is believed to occur due to nursing shortage and high patient/nurse ratio.

E1: ... a service of 43-44 people, including the private service. On some days we really can't keep up with anything... We can't stay with a patient for hours; we just do the task at hand and leave.

The majority of nurses reported having difficulties due to the expectations of patients and management.

$\mathrm{K}$ : Patients complain about that saying "the nurse visited us too late, didn't remove the IV for so long." ... it really stresses me when I can't reach people on time.

One of the nurses declared that his/her workload increased because s/he couldn't manage the caregiver s/he was working with. The same nurse also described the unit s/he worked in as risky because too many verbal orders are given:

E2: It is risky. For example, consider a patient with no orders for three days. Too many verbal orders are given here.

Some nurses declared that they had communication difficulties with nurses mainly due to their heavy workload while they were still students themselves. Communication difficulty was defined as "being used as a tool $(\mathrm{N})$, being forced to run errands $(\mathrm{G})$, not being allowed to intervene, and intolerance." Some nurses pointed out that as a student, they thought that nursing was only about treating patients. The nurses also stated that they could not put their training into practice due to heavy workload:

E1: Time and staff numbers affect us... for example we would wipe all ampoules with Batticon while in school... now if we try to that, we can't do the actual work.

\section{Discussion}

The themes identified in this study were communication difficulties, lack of skills, lack of knowledge, and heavy workload, which support the findings of other studies on the early employment years of newly graduated nurses. ${ }^{[17]}$

Published by Sciedu Press

\subsection{Communication difficulties}

The importance of the communication between nurses and a supportive approach during a new graduate's transition into nursing is emphasized. ${ }^{[18]}$ In this study, some nurses reported encountering situations where work was handed over while changing shifts. In Maben et al.' ${ }^{[12]}$ study, in expressions coded as "not shirking", nurses expressed that they felt guilty when handing over incomplete tasks and did so with expressions that have apologetic connotations. While shirking meant leaving their uncompleted work for the other nurse in their study, it meant intentionally increasing the other's workload or not helping the other. Gülerbaşl1-İleri's ${ }^{[8]}$ study investigating the stress factors affecting the newly-graduated nurse's adaptation to clinic, $32.4 \%$ of the nurses reported working with nurses that are not willing to help. This rate is $34.6 \%$ in Çalışkan's study. ${ }^{[10]}$

The statements nurses made about having felt they were watched to catch their shortcomings, having been scolded, and being unable to become a part of their team demonstrates the hierarchy between the newly-graduated and experienced nurses. It has been reported that due to lack of confidence, newly-graduated nurses form hierarchical relationships with experienced nurses and physicians rather than colleague relationships. ${ }^{[19]}$ Some studies pointed out the communication difficulties experienced with physicians and reasoned that such difficulties occurred due to the newly-graduated nurses' lack of knowledge or the negative behaviors of the physicians. ${ }^{[7,17]}$ In O'Shea and Kelly's ${ }^{[9]}$ study, a nurse expressed the reason for difficulties in nurse-physician communications as "Physicians never talked to us when we were students; you couldn't get close or ask questions. The moments we put on our uniforms, they expected us to do something." It is pointed out that nurses have better skills in communicating with health professionals as their knowledge and experience increases, and that the nurses need to use their critical thinking skills to decide when and how they will communicate with physicians. ${ }^{[17]}$ In this study, the reason for the difficulties experienced in communications with physicians can be explained as their inability to communicate with physicians while they were students and the negative behaviors of the physicians.

\subsection{Lack of clinical skills}

McKenna and Green ${ }^{[20]}$ indicated that new graduates focus mainly on clinical knowledge and skills during their first six months and try to cope with this. O'Shea and Kelly's ${ }^{[9]}$ qualitative study on the other hand noted that rather than routine clinical skills, the new graduates experience inadequacy mainly in the particular non-routine tasks such as inserting 
nasogastric tube, aspiration, removal central catheter, percutaneous endoscopic gastrostomy tube, and tracheostomy. In this study, ${ }^{[9]}$ a nurse mentioned having the "fear of killing a patient" in her early days while aspirating patients:

"Suctioning, we didn't do a lot of that when we were training we just watched as well, 'cos there was no pressure on us to do it'."

In our study, nurses reported experiencing lack of clinical skills, which confirms the findings in literature. ${ }^{[13]}$ While starting IVs, mentioned by a majority of the nurses in this study as a lack of clinical skills, is technically a routine skill, it may require a different approach for each patient, specifically pediatric patients. The major theme in Kelly and Courts's ${ }^{[21]}$ study with new graduates on what they recommend for their formal education was increasing clinical experience. Regarding the inadequacy mentioned in this study in use of medical devices, Çalışkan ${ }^{[10]}$ reported that $23.6 \%$ of the newly-graduated nurses experience stress due to not knowing how to use/operate materials/equipment.

\subsection{Lack of knowledge}

Prior studies remark that newly-graduated nurses have a fear of making a mistake because of the increased workload and responsibility. ${ }^{[8]}$ On the other hand, $88.1 \%$ of the newlygraduated nurses evaluated themselves as good or advanced in drug management in Lofmark et al.' 's ${ }^{[1]}$ study. In qualitative studies, nurses reported more specifically that they have difficulties in drug management. They report having checked drugs over and over and being afraid of making a mistake when administering drugs in absence of a guiding nurse. ${ }^{[7,9]}$ Statements coded as lack of drug knowledge do not fully cover drug management. Lack of knowledge was expressed specifically on drug content, commercial and generic brand differences, and effects. In addition, difficulties in calculating drug dosage for pediatric patients were also mentioned. In Kelly and Courts's ${ }^{[21]}$ study, nurses recommended increasing pediatric pharmacology courses in their educational curriculum.

Some of the nurses have also reported lack of knowledge of diseases and the performed surgeries. This is interpreted as being due to the hospital they worked at being a tertiary teaching hospital and high variety of disease profiles. Regarding laboratory results, a nurse's statement of seeing them as a physician's duty, not focusing on it as a student, and feeling a need for this as a professional nurse is considered an important finding by the researchers. Nurses also reported having difficulties in communications with physicians and patients' relatives due to their lack of knowledge and experiencing fear of being unable to answer questions. ${ }^{[17,22]}$
Notwithstanding, the nurses in this study generally reported having kept learning on the job by researching themselves and asking nurses and physicians questions.

\subsection{Heavy workload}

In prior studies conducted with newly-graduated nurses, heavy workload is cited as the leading factor among the organizational factors. Time shortage due to heavy workload causes inability to spend enough time with patients, rushing tasks, and fearing making mistakes due to making quick decisions and taking care of multiple patients and tasks at a time ${ }^{[1-3,8-10,12]}$ Another meaning attributed to heavy workload in this study was taking care of service tasks outside of nursing care. Duchscher ${ }^{[19]}$ reported that focusing on tasks such as admissions, answering the phone, and requesting tests that occur in not sufficiently developed institutions, take away from the time that is spared for the patient and his/her relatives. O'Kane's ${ }^{[23]}$ study with intensive care unit nurses reported that their greatest difficulty was time management. Nurses defined a "good day" as a day when they were able to control everything and were able to complete their records on time. Similarly, in this study, nurses reported not being able to spend enough time with patients and that they were unable to provide the ideal nursing care they were taught about, meaning that they could not put education into practice.

Another nurse complained that her unit was risky due to the use of too many verbal orders. This finding points out that the nurses who start to work in this unit are at higher risk of making drug-related mistakes. Use of verbal orders suggests that the physician and the unit are suffering from heavy workload. Considering that many of the nurses have difficulties when faced with verbal orders due to limited drug knowledge, verbal orders will increase the risk of nurses making mistakes. Difficulty reaching physicians was defined as an organizational factor leading to stress for newly-graduated nurses as well. ${ }^{[17]}$

Studies show that newly-graduated nurses have difficulties in managing the assisting staff they work with. ${ }^{[19]}$ Similarly, literature includes reports of assistant staff not responding to questions from, not assisting, and not completing tasks assigned by newly-graduated nurses. ${ }^{[17]}$ A participant in this study mentioned that $\mathrm{s} / \mathrm{he}$ has been increasing her own workload because s/he can not manage his/her patient caregiver staff. This finding shows that nurses have a hard time assigning tasks to the caregiver staff. Similarly, literature includes reports of assistant staff not responding to questions from, not assisting, and not completing tasks assigned by newly-graduated nurses. ${ }^{[17]}$ As a result it can be concluded that heavy workload creates communication difficulties with colleagues and other members of the work teams. 
The report of a nurse in this study stating that s/he had envisioned nursing as only treating patients as a student due to his/her role models during internships and of student nurses being used by experienced nurses on side tasks is considered a critical finding in terms of indicating heavy workload and as a factor hindering communication in the workplace. Similarly, it is expected that the job satisfaction of the newlygraduated nurses who can not apply their knowledge due to heavy workload will be negatively affected.

\section{Conclusion}

Evaluation of the professional and organizational factors that impact the adaptation process of newly-graduated nurses is important to revise the curriculum for educator nurses and to provide the organizational support for nurse managers. For the past thirty years, studies on this matter have been conducted investigating specifically the experiences of newly-graduated nurses in the first few months of employment, in terms of their emotions, difficulties, job satisfaction, intention to quit work, and evaluation of guidance practices, along with their evaluation by nurses and managers. It has been observed that the difficulties and stress experienced by newly-graduated nurses are understood in more detail via qualitative studies. In this study, as the first qualitative study conducted with newly-graduated nurses in Turkey, we determined that the difficulties newly-graduated nurses experience within the first few months of their employment are communication difficulties, mostly starting IVs in terms of clinical skills, and lack of knowledge specifically in pharmacology, accompanied by the effects of high patient/nurse ratio on their job satisfaction and communication within teams. In order to reduce these experienced difficulties, it may be recommended to employ unit-specific orientations adapted to the needs of the newly-graduated nurses in addition to general orientations. The newly-graduated nurses should be offered training prior to or on their first day of employment on diseases, surgeries, laboratory results, most frequently used drugs and their effects, and drug preparation. The effectiveness of the increasingly used guidance practices should also be evaluated.

\section{Conflicts OF InTEREST Disclosure}

The authors declare that there is no conflict of interest.

\section{REFERENCES}

[1] Lofmark A, Smide B, Wikblad K. Competence of newly-graduated nurses-a comparison of the perceptions of qualified nurses and students. Journal of Advanced Nursing. 2006; 53(6): 721-728. http://dx.doi.org/10.1111/j.1365-2648.2006.03778.x

[2] Mooney M. Professional socialization: The key to survival as a newlyqualified nurse. International Journal of Nursing Practice. 2007; 13: 75-80. http://dx.doi.org/10.1111/j.1440-172X.2007 $.00617 . x$

[3] Feng RF, Tsai YF. Socialisation of new graduate nurses to practising nurses. Journal of Clinical Nursing. 2011; 21: 2064-2071. http://dx.doi.org/10.1111/j.1365-2702.2011.03992.x

[4] Chandler GE. Succeeding in the first year of practice. Journal for Nurses in Staff Development. 2012; 28(3): 103-107. http: //dx.doi.org/10.1097/NND.0b013e31825514ee

[5] Marks-Maran D, Ooms A, Tapping J, et al. A preceptorship programme for newly-qualified nurses: A study of preceptees' perceptions. Nurse Education Today. 2013; 33: 1428-1434. http: $/ /$ dx.doi.org/10.1016/j.nedt.2012.11.013

[6] Horsburg D, Ross J. Care and compassion: the experiences of newlyqualified staff nurses. Journal of Clinical Nursing. 2013; 22: 11241132. http://dx.doi.org/10.1111/jocn. 12141

[7] Maben J, Macleod-Clark J. Project 2000 diplomates' perceptions of their experiences of transition from student to staff nurse. Journal of Clinical Nursing. 1998; 7: 145-153. http://dx.doi.org/10.10 46/j.1365-2702.1998.00119.x

[8] Gülerbaşl1- İleri S. Examining the perception of the transition period of the professional roles of newly-graduated nurses [master's thesis]. [Izmir]: Dokuz Eylul University Institute of Health Sciences; 2007. $70 \mathrm{p}$.
[9] O'Shea M, Kelly B. The lived experiences of newly-qualified nurses on clinical placement during the first six months following registration in the Republic of Ireland. Journal of Clinical Nursing. 2007; 16: 1534-1542. http://dx.doi.org/10.1111/j.1365-2702. 2006 $.01794 . \mathrm{x}$

[10] Çalışkan A. Examining job satisfaction burnout and reality shock amongst newly-graduated nurses [master's thesis]. [Istanbul]: Marmara University Institute of Health Sciences; 2010. 159 p.

[11] Kramer M, Brewer BB, Halfer D, et al. Changing our lens: seeing the chaos of professional practice as complexity. Journal of Nursing Management. 2013; 21: 690-704. http://dx.doi.org/10.1111 /jonm. 12082

[12] Maben J, Latter S, Macleod-Clark J. The theory-practice gap: impact of professional-bureaucratic work conflict on newly-qualified nurses. Journal of Advanced Nursing. 2006; 55(4): 465-477. http: //dx.doi.org/10.1111/j.1365-2648.2006.03939.x

[13] Uzun S, Arslan F. Experiences and recommendations of newlygraduated nurses at the end of their first years of employment. Turkiye Klinikleri Journal of Medical Ethics. 2009; 17(1): 17-22.

[14] Tastan S, Unver V, Hatipoglu S. An analysis of the factors affecting the transition period to professional roles for newly-graduated nurses in Turkey. International Nursing Review. 2013; 60: 405-412. http://dx.doi.org/10.1111/inr.12026

[15] Patton M. Qualitative evaluation and research methods. Beverly Hills, CA: Sage, 1990.

[16] Strauss A, Corbin J. Basics of Qualitative Research: Grounded Theory Procedures and Techniques. Newbury Park, CA: Sage Publications; 1990.

[17] Pfaff K, Baxter P, Jack S, et al. An integrative review of the factors influencing new graduate nurse engagement in interprofessional 
collaboration. Journal of Advanced Nursing. 2014; 70(1): 4-20. http://dx.doi.org/10.1111/jan.12195

[18] Gohery P, Meaney T. Nurses' role transition from the clinical ward environment to the critical care environment. Intensive and Critical Care Nursing. 2013; 29: 321-328. http://dx.doi.org/10.1016 /j.iccn.2013.06.002

[19] Duchscher J. Transition shock: the initial stage of role adaptation for newly-graduated registered nurses. Journal of Advanced Nursing. 2008; 65: 1103-1113. http://dx.doi.org/10.1111/j.1365-2 648.2008.04898.x

[20] McKenna L, Green JM. After the graduate year: a phenomenological exploration of how new nurses develop their knowledge and skill over the first 18 months following graduation. Australian Journal of Advanced Nursing. 2004; 25(4): 9-15.

[21] Kelly S, Courts N. The professional self-concept of new graduate nurses. Nurse Education in Practice. 2007; 7: 332-337. http: //dx.doi.org/10.1016/j.nepr.2006.10.004

[22] Yeh MC, Yu S. Job stress and intention to quit in newly-graduated nurses during the first three months of work in Taiwan. Journal of Clinical Nursing. 2009; 18: 3450-3460. http: //dx. doi .org/10. 1111/j.1365-2702.2009.02941.x

[23] O'Kane CE. Newly-qualified nurses' experiences in the intensive care unit. Nursing in Critical Care. 2011; 17(1): 44-51. http: //dx.doi.org/10.1111/j.1478-5153.2011.00473.x 